\title{
Kabuki Make-up (Niikawa-Kuroki) Syndrome: Dental and Craniofacial Findings in a Brazilian Child
}

\author{
Bianca Mota dos SANTOS \\ Roberta Rezende RIBEIRO \\ Adriana Sasso STUANI \\ Francisco Wanderley Garcia de Paula e SILVA \\ Alexandra Mussolino de QUEIROZ \\ Department of Pediatric Clinics, Preventive and Social Dentistry, \\ School of Dentistry of Ribeirão Preto, University of São Paulo, Ribeirão Preto, SP, Brazil
}

\begin{abstract}
This article reports the case of a Brazilian child diagnosed with Kabuki make-up syndrome (KMS), addressing the clinical features observed, with emphasis on the disease-specific oral and craniofacial manifestations. The patient had the distinctive KMS craniofacial appearance, mild delayed mental development, fingers with prominent fingertip pads and visual deficit. The dental findings included fusion of the left mandibular incisors (central and lateral), gemination of the right mandibular central incisor and congenital agenesis of the right mandibular lateral incisor, in the primary dentition, as well as absence of both permanent mandibular lateral incisors. Fusion and gemination have not been previously referred to as typical dental features in KMS. The detection of unique dental findings, such as missing teeth and dental anomalies of form in the primary dentition by means of clinical and radiographic examinations, might consist of a helpful diagnosis parameter in identifying children who may have milder forms of Kabuki syndrome.
\end{abstract}

Key Words: Kabuki make-up syndrome, Kabuki syndrome, special needs patients, dental anomalies.

\section{INTRODUCTION}

Kabuki make-up syndrome (KMS) was first described in 1981 by Niikawa et al.(1) and Kuroki et al. (2), in two independent studies involving unrelated children at two Japanese centers in the Kanto area and Hokkaido. This syndrome is a rare genetic disorder (3) and, although its etiology is unclear (4-6), an autosomal dominant pattern of inheritance with variable expression has been suggested $(2,7,8)$. In most cases, the patients do not present a family history of the syndrome (9).

The clinical diagnosis of KMS is based on the presence of five primary characteristics (cardinal manifestations), which are a distinctive facies (100\% of the cases), dermatoglyphic anomalies (93\%), skeletal abnormalities (92\%), mild-to-moderate mental retardation
(92\%) and postnatal growth failure with short stature (83\%) (9). The craniofacial manifestations of KMS include epicanthus, strabismus, long palpebral fissures with eversion of the lateral part of the lower eyelid, higharched eyebrows with sparse lateral one-third, large eyes, blue sclera, long and curved eyelashes, short nasal septum, broad depressed nasal root with flat nasal tip, preauricular dimple, prominent cup-shaped ears and low posterior hairline (1-8, 10-19). These features give the patients a peculiar mask-like facies. The designation of Kabuki syndrome was labeled because the peculiar facial appearance of the affected individuals resembled to that created by the make-up used by the "Kabuki" (the traditional Japanese theater) actors (1).

Oral manifestations are commonly observed in KMS (68\% of the cases) and may comprise microg-

Correspondence: Profa. Alexandra Mussolino de Queiroz, Departamento de Clinica Infantil, Odontologia Preventiva e Social, Faculdade de Odontologia de Ribeirão Preto, USP, Avenida do Café S/N, 14040-904 Ribeirão Preto, SP, Brasil. Tel: +55-16-3602-4116. Fax: +55-163633-0999. e-mail: amqueiroz@forp.usp.br 
nathia, retrognathia, high-arched palate, posterior crossbite, cleft lip/palate, bifid tongue and uvula, widely spaced teeth, ectopic permanent first molars, delayed tooth eruption pattern, external root resorption of the permanent upper incisors and molars, impacted teeth and dental anomalies such as hypodontia, conical teeth, neonatal teeth and teeth with large pulp chamber (1-18).

Other frequent findings in KMS patients are susceptibility to infections, generalized muscular hypotonia, joint laxity, visual and hearing deficiencies, congenital heart defects, skeletal and genitourinary tract abnormalities (1-7,10-11,13,15,17,18). Although Kabuki make-up syndrome has been widely investigated from a medical standpoint, few reports have focused on the oral characteristics of affected patients.

This article documents the case of a Brazilian child diagnosed with Kabuki make-up syndrome, addressing the clinical features observed, with emphasis on the disease-specific dental and craniofacial findings. Oral manifestations previously described in the literature and those observed in our patient are confronted.

\section{CASE REPORT}

A 3-year-and-2-month old male child diagnosed with Kabuki make-up syndrome by Genetics Department of the Clinics Hospital of Ribeirão Preto (University of São Paulo), was brought to the clinic of the Center of Formation of Human Resources Specialized in Dental Care for Special Patients (School of Dentistry of Ribeirão Preto, University of São Paulo) for general

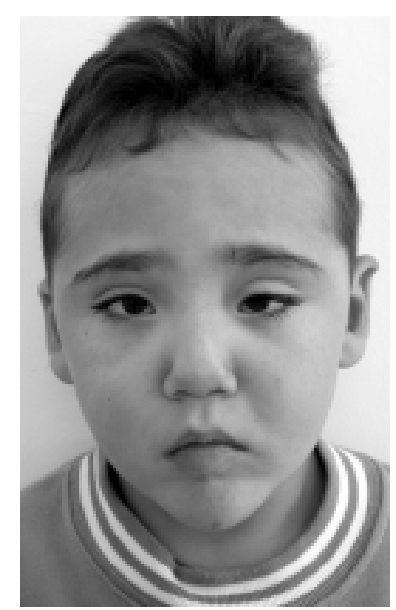

Figure 2. Frontal view of the patient showing the peculiar, distinctive craniofacial features of Kabuki make-up syndrome. dental care. Chief complaint was the presence of two teeth with abnormal form in the mandibular arch.

The child was born to healthy nonconsanguineous Caucasian parents after full-term, uneventful pregnancy and had been diagnosed with KMS. Family history for the syndrome was denied. Medical history and physical examination revealed stature compatible with his chronological age, fingers with prominent fingertip pads (Fig. 1), a distinctive facies consisting of high-arched eyebrows with sparse lateral one-third, eyes with eversion of the lateral one-third of the lower eyelids, long and curved eyelashes, palpebral ptosis, visual deficit accompanied by strabismus in the left eye, blue sclera, prominent ears, broad depressed nasal root with flat nasal tip, tent-shaped mouth (Figs. 2 and 3)

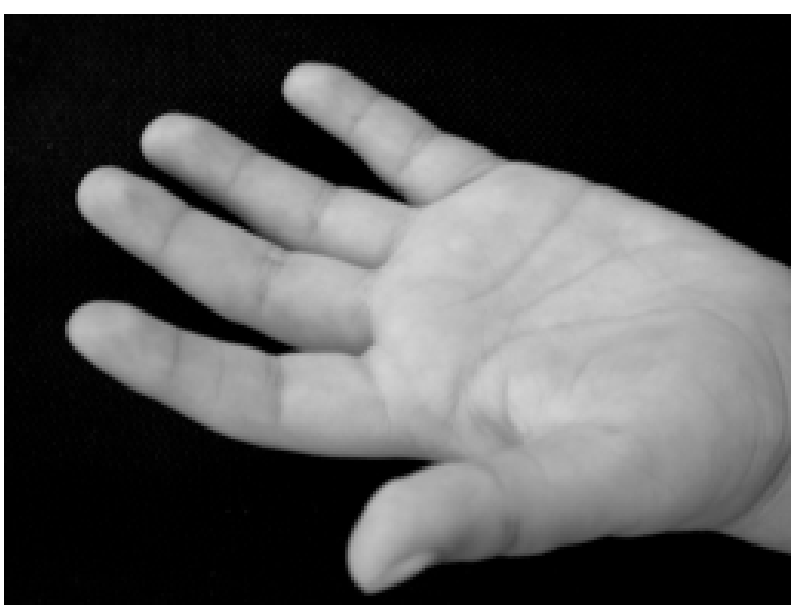

Figure 1. Prominent fingertip pads.

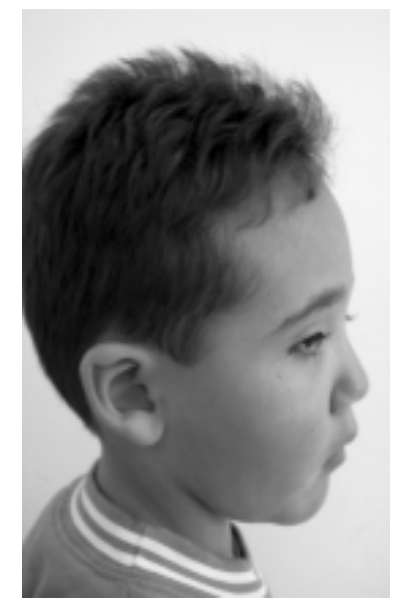

Figure 3. Lateral view of the patient showing the broad depressed nasal root with flat nasal tip. 
and mild delayed mental development.

Intraoral examination showed anterior open bite and dental anomalies of form/number in the mandibular incisor region (Fig. 4), which were confirmed on panoramic and periapical radiographs (Figs. 5 and 6) as fusion of the primary left mandibular central and lateral incisors and gemination of the primary right mandibular central incisor. Congenital absence of primary and permanent right mandibular lateral incisors and permanent left mandibular lateral incisor was also noted.

The dental treatment included prophylaxis, topical applications of $1.23 \%$ acidulated phosphate-fluoride gel, restoration of the geminated right mandibular central incisor with composite resin and sealing of the groove caused by the fusion of left mandibular central and lateral incisors with a resin-based sealant to prevent

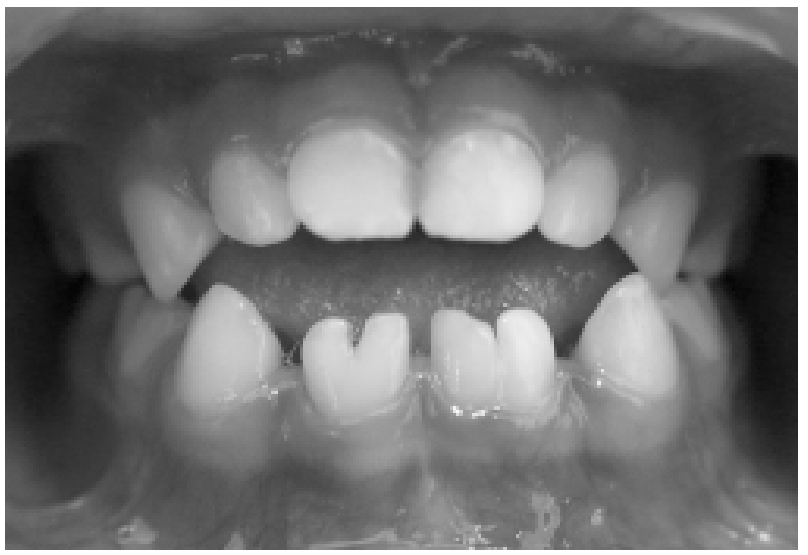

Figure 4. Intraoral view showing the anterior open bite and dental anomalies of form and number in the mandibular incisal region.

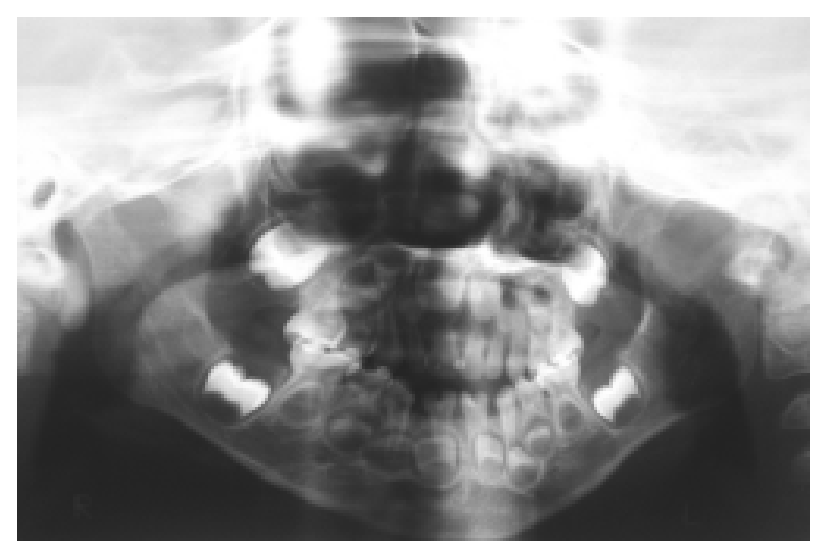

Figure 5. Panoramic radiograph showing fusion of teeth 71 and 72, gemination of tooth 81 and absence of teeth 82, 32 and 42 . caries onset. The parents received information on caries disease and oral health care, training on mechanical plaque removal and counseling on a low-sucrose diet. They were advised about the missing permanent mandibular lateral incisors and that dental anomalies of form could develop in other permanent teeth. Parental written informed consent was obtained for case report and disclosure of child's uncovered photographs.

\section{DISCUSSION}

The etiology of KMS is unknown $(4,6,8,15,19,20)$ and this disorder usually manifests as sporadic cases within a same family. The findings of this case report are consistent with these characteristics. However, there have been reports of families with clinical manifestations of KMS in one of the parents and their offspring (11), which raises the assumption of an autosomal dominant pattern of inheritance with variable expressivity (8). Although several KMS cases have been described with different chromosomal anomalies, none had an autosomal cytogenetic aberration in common (20). The hypothesis that KMS would be related to an altered expression of $\mathrm{X}$ chromosome loci has also been postulated $(2,11,13,19)$. Duplication of the 8p22-8p23.1 region has been shown by comparative genomic hybridization (CGH) in $6 \mathrm{KMS}$ patients and, as they belonged

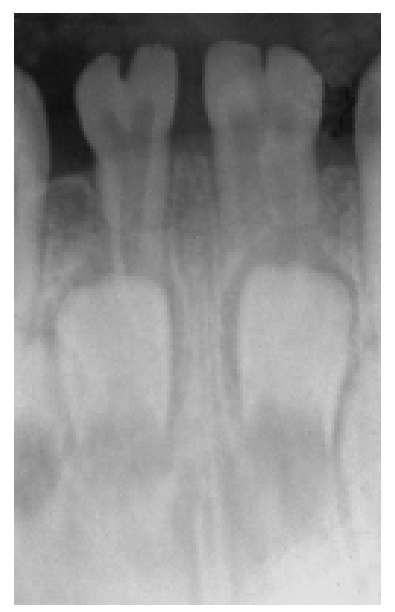

Figure 6. Periapical radiograph of the mandibular incisors showing dental anomalies of form (fusion and gemination). Note the fusion of the left mandibular central and lateral incisors (two individual roots, two root canals and two joined crowns). The right mandibular central incisor has one root, one root canal and a partially bifid dental crown, typical signs of germination. 
to different ethnical groups, this duplication may represent a common etiologic basis for this disorder (20).

In contrast with the findings of most reports (14,7-8,10,14,17-20), which support that KMS individuals typically present postnatal growth deficiency, the child presented in this paper had stature compatible with his age. Patients with Kabuki syndrome and normal growth have also been described $(3,6,13,14)$. According to White et al. (18), low stature in KMS is actually less common than previously assumed.

Oral manifestations described in 17 groups of patients with Kabuki make-up syndrome from 1981 to 2004 as well as the findings observed in the child of this article are summarized in Table 1. Dental anomalies are a common finding in KMS (19) and are present in over $70 \%$ of the affected individuals. Hypodontia and widely spaced teeth are observed in over 1/3 of KMS patients (7). These clinical features may be helpful in establishing the diagnosis of the disease and identifying mildly affected carrier parents $(7,8)$. The child hereby described had congenital agenesis of the permanent mandibular lateral incisors and the primary right mandibular lateral incisor. Although his parents did not show any identifiable abnormality in the dentition, it is not possible to unequivocally affirm that they lacked dental anomalies because both had been submitted to multiple extractions and extensive restorative/prosthetic rehabilitation.

The most interesting dental findings of our patient were the dental fusion and gemination. The phenomenon of gemination arises when a developing tooth bud attempts to split but fails to do so completely, resulting in a tooth with an enlarged crown and normal root. In cases of gemination, the number of teeth is normal. Fusion designates the union of two teeth by dentin. The joined crowns appear as one "enlarged crown" and tooth counting reveals a missing element.

As far as it could be ascertained, this case report is the first one to describe the presence of such dental anomalies of form in the primary dentition of a child diagnosed with Kabuki syndrome, probably because most articles dealing with KMS have discussed the clinical manifestations from a medical standpoint and few reports have specifically described the orodental findings in affected individuals. Therefore, it is possible that there have been a generalization regarding the types of dental anomalies usually observed in KMS patients. Further studies should investigate whether this apparent association is, indeed, consistent. Meanwhile, we can only speculate that dental fusion and germination may be added to the constellation of orodental features typically found in patients with Kabuki syndrome. The tentshaped appearance of our patient's mouth has been previously described $(12,17)$ and the anterior open bite, which was not associated with any non-nutritive sucking habits, was reported in only one study (14).

Description of new cases of Kabuki syndrome in different ethnical groups is important because of the reportedly low incidence of this syndrome outside Japan. To date, nearly 350 cases have been documented worldwide. Non-Japanese KMS patients documented thus far include nearly 74 Caucasians $(4,6,8,10-11,13)$, 2 Afro-Americans (6), 3 Arabs (5,6), 12 Spanish (6,13), 1 Indian (6), 24 Australians (18), 3 New Zealanders (18), 1 South American (4) and 1 Brazilian (12). This case report confirms previous findings suggesting that, although KMS is more prevalent in Oriental, it may affect individuals of other ethnical groups alike.

The child of this article matches several clinical criteria described by Niikawa et al. (1) and Kuroki et al. (2). The craniofacial appearance is characteristic of KMS patients, consisting of high-arched eyebrows with sparse lateral one-third, eyes with eversion of the lateral one-third of the lower eyelids specially the left one, long and curved eyelashes, palpebral ptosis, strabismus, blue sclera, visual deficiency, prominent ears and broad depressed nasal root with flat nasal tip. Nevertheless, the child did not have cleft lip or palate, which has been reported in $41 \%$ of the patients by Niikawa et al. (9). Accordingly, cleft lip and cleft palate have been described as typical oral findings in KMS in a large number of case reports $(4,5,8,11,13,14,16-18)$.

KMS individuals often have a history of delayed intellectual development and language acquisition. Niikawa et al. (9) reported that mental and speech impairments were present in 57 of 62 patients examined (92\%). Our patient also had a mild intellectual deficit.

Other neurological anomalies possibly manifesting in KMS include microcephaly, brachcephaly, hypotonia, cerebellar atrophy and trigonocephaly (3,5,9$11,13,17)$. None of these features, however, were observed in the patient of this article. In addition, unlike the findings of previous reports $(2,4,8,10,11,17,18)$, the child did not show hearing loss, joint laxity or genitourinary abnormalities. Dermatoglyphic anomalies have been found in the majority of the individuals with KMS (96\%) $(1,2,4,6-8,10,11,15,17)$. In the child we 


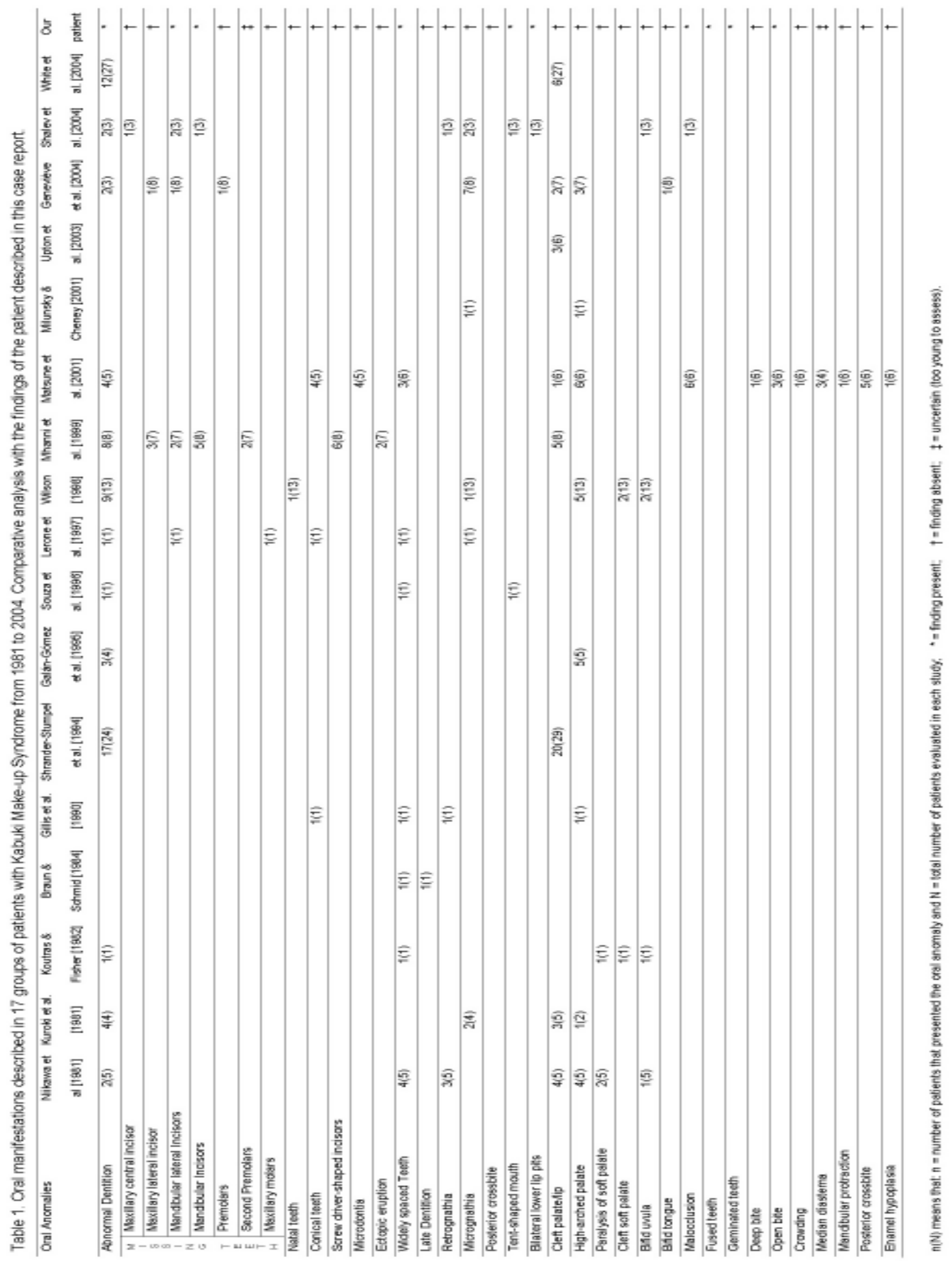


describe, the only dermatoglyphic anomaly were the prominent fingertip pads in all fingers.

Cardiac problems are found in nearly $42 \%$ of affected individuals. The patient shown in this case report, however, did not present detectable heart defects, which is in agreement with the findings of previous reports $(3,6-8,10,11,13,15,17)$. It should be emphasized that the existence of congenital cardiac abnormalities in KMS patients make them of high risk for bacterial endocarditis and therefore administration of an antibiotic regimen for prophylaxis of infections before invasive dental procedures is a highly advisable approach.

In conclusion, Kabuki syndrome is primarily diagnosed on the basis of clinical features and, up to date, its etiology remains unclear. Investigation of dental manifestations is important because the identification of unique dental findings, such as missing teeth and dental anomalies of form in the primary and permanent dentitions, may be a helpful parameter to substantiate the diagnosis of Kabuki syndrome in children with mild forms of the disease. In addition, clinical and radiographic examination of the dentition of KMS children's parents is recommendable to seek for dental anomalies that may help identifying mildly affected carrier parents.

\section{RESUMO}

Este artigo relata o caso de uma criança portadora da Síndrome de Kabuqui e descreve as características clínicas observadas, com ênfase nas manifestações craniofaciais e intrabucais. O paciente apresentava características craniofaciais clássicas da síndrome, deficiência mental leve, déficit visual e atraso no desenvolvimento dental. Os achados intrabucais incluíam a fusão dos incisivos inferiores do lado esquerdo (central e lateral), geminação do incisivo central inferior direito e agenesia do incisivo lateral inferior direito na dentição decídua bem como ausência dos incisivos laterais inferiores permanentes. Fusão e geminação ainda não foram descritas em pacientes com a síndrome. Assim, a detecção de achados dentais como agenesias e anomalias de forma na dentição decídua, por meio de exames clínicos e radiográficos, são importantes para auxíliar no diagnóstico de crianças com uma forma moderada da Síndrome de Kabuqui.

\section{REFERENCES}

1. Niikawa N, Matsuura N, Fukushima Y, Ohsawa T, Kajii T. Kabuki make-up syndrome: A syndrome of mental retardation, unusual facies, large and protruding ears, and postnatal growth deficiency. J Pediatr 1981;99:565-569.

2. Kuroki Y, Suzuki Y, Chyo H, Hata A, Matsui I. A new malformation syndrome of long palpebral fissures, large ears, depressed nasal tip, and skeletal anomalies associated with postnatal dwarfism and mental retardation. J Pediatr 1981;99:570-573.

3. Genevieve D, Amiel J, Viot G, Le Merrer M, Sanlaville D, Urtizberea A, Gerard M, Munnich A, Cormier-Daire V, Lyonnet S. Atypical findings in Kabuki Syndrome: Report of 8 patients in a series of 20 and review of the literature. Am J Med Gen 2004;129:64-68.

4. Koutras A, Fisher S. Niikawa-Kuroki Syndrome: A new malformation syndrome of postnatal dwarfism, mental retardation, unusual face, and protruding ears. J Pediatr 1982;101:417-419.

5. Gillis R, Klar A, Gross-Kieselstein E. The Niikawa-Kuroki (Kabuki make-up) syndrome in a Moslem Arab child. Clin Gen 1990;38:378-381.

6. Galán-Gómez E, Cardesa-García JJ, Campo-Sampedro FM, Salamanca-Maesso C, Martínez-Frías ML, Frías JL. Kabuki make-up (Niikawa-Kuroki) syndrome in five Spanish children. Am J Med Gen 1995;59:276-282.

7. Lerone M, Priolo M, Naselli A., Vignolo M, Romeo G, Silengo MC. Ectodermal abnormalities in Kabuki syndrome. Am J Med Gen 1997;73:263-266.

8. Mhanni AA, Cross HG, Chudley AE. Kabuki syndrome: description of dental findings in 8 patients. Clin Genet 1999;56:154-157.

9. Niikawa N, Kuroki Y, Kajii T, Matsuura N, Ishikiriyama S, Tonoki $\mathrm{H}$ et al. Kabuki make up (Niikawa-Kuroki) syndrome: a study of 62 patients. Am J Med Gen 1988;3:564-589.

10. Braun $\mathrm{OH}$, Schmid E. Kabuki makeup syndrome (NiikawaKuroki syndrome) in Europe. J Pediatr 1984;105:849-850.

11. Schrander-Stumpel C, Meinecke P, Wilson G, GillessenKaesbach G, Tinschert S et al. The Kabuki (Niikawa-Kuroki) syndrome: further delineation of the phenotype in 29 nonJapanese patients. Eur J Pediatr 1994;153:438-445.

12. Souza JC, Ribeiro TCC, Ribeiro RC. Kabuki make-up syndrome. J Pediatria 1996;72:341-344.

13. Wilson GN. Thirteen cases of Niikawa-Kuroki Syndrome: Report and review with emphasis on medical complications and preventive management. Am J Med Gen 1998;79:112120.

14. Matsune K, Shimizu T, Tohma T, Asada Y, Ohashi H, Maeda T. Craniofacial and dental characteristics of Kabuki Syndrome. Am J Med Gen 2001;98:185-190.

15. Milunsky JM, Cheney SM. Kabuki Syndrome in a Haitian patient. Am J Med Gen 2001;100:172-174.

16. Upton S, Stadter CS, Landis P, Wulfsberg EA. Speech characteristics in the Kabuki Syndrome. Am J Med Gen 2003;116A:338-341.

17. Shalev SA, Clarke LA, Koehn D, Langlois S, Zackai EH, Hall JG, et al. Long-term follow-up of three individuals with Kabuki Syndrome. Am J Med Gen 2004;125A:191-200.

18. White SM, Thompson EM, Kidd A, Savarirayan R, Turner A, Amor D, et al. Growth, behavior, and clinical findings in 27 patients with Kabuki (Niikawa-Kuroki) Syndrome. Am J Med Gen 2004;127A:118-127.

19. Adam MP, Hudgins L. Kabuki syndrome: a review. Clin Genet 2004;67:209-219.

20. Milunsky JM, Huang JM. Unmasking kabuki syndrome: chromosome 8p22-8p23.1 duplication reveled by comparative genomic hybridization and BAC-FISH. Clin Genet 2003;64:509-516. 